\title{
Article
}

\section{Thermal Analysis of an Oil Jet-Dry Sump Transmission Gear under Mixed- Elastohydrodynamic Conditions}

Fatourehchi, E, Shahmohamadi, H, Mohammad Pour, M, Rahmani, $\mathrm{R}$, Theodossiades, $\mathrm{S}$ and Rahnejat, $\mathrm{H}$

Available at https://clok.uclan.ac.uk/32099/

Fatourehchi, E, Shahmohamadi, H, Mohammad Pour, M, Rahmani, R, Theodossiades, $S$ and Rahnejat, $H$ (2018) Thermal Analysis of an Oil Jet-Dry Sump Transmission Gear under Mixed-Elastohydrodynamic Conditions. Journal of Tribology, 140 (5). 051502.

It is advisable to refer to the publisher's version if you intend to cite from the work. http://dx.doi.org/10.1115/1.4039567

For more information about UCLan's research in this area go to http://www.uclan.ac.uk/researchgroups/ and search for <name of research Group>.

For information about Research generally at UCLan please go to http://www.uclan.ac.uk/research/

All outputs in CLoK are protected by Intellectual Property Rights law, including Copyright law. Copyright, IPR and Moral Rights for the works on this site are retained by the individual authors and/or other copyright owners. Terms and conditions for use of this material are defined in the policies page.

\section{CLoK}

Central Lancashire online Knowledge www.clok.uclan.ac.uk

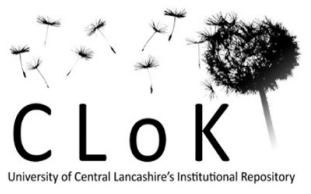


This item was submitted to Loughborough's Research Repository by the author.

Items in Figshare are protected by copyright, with all rights reserved, unless otherwise indicated.

\section{Thermal analysis of an oil jet-dry sump transmission gear under mixed- elastohydrodynamic conditions}

PLEASE CITE THE PUBLISHED VERSION

https://doi.org/10.1115/1.4039567

\section{PUBLISHER}

(C) ASME (American Society of Mechanical Engineers)

\section{VERSION}

AM (Accepted Manuscript)

\section{PUBLISHER STATEMENT}

This work is made available according to the conditions of the Creative Commons Attribution 4.0 Unported Licence (CC BY). Full details of this licence are available at: http://creativecommons.org/licenses/by/4.0/

\section{LICENCE}

CC BY 4.0

\section{REPOSITORY RECORD}

Fatourehchi, Ehsan, Hamed Shahmohamadi, Mahdi Mohammadpour, Ramin Rahmani, Stephanos Theodossiades, and Homer Rahnejat. 2019. "Thermal Analysis of an Oil Jet-dry Sump Transmission Gear Under Mixed-elastohydrodynamic Conditions”. figshare. https://hdl.handle.net/2134/28373. 


\section{American Society of Mechanical Engineers}

SETTING THE STANDARD

\section{ASME Accepted Manuscript Repository}

\section{Institutional Repository Cover Sheet}

ASME Paper Title: Thermal analysis of an oil jet-dry sump transmission gear under mixed-elastohydrodynamic

conditions

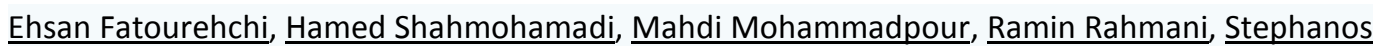

Authors: $\quad$ Theodossiades and Homer Rahnejat

ASME Journal Title: Journal of Tribology

Volume/Issue $140(5)$

Date of Publication (VOR* Online) 26 April

2018

ASME Digital Collection URL: http://tribology.asmedigitalcollection.asme.org/article.aspx?articleid=2675232

DOI:

*VOR (version of record) 


\title{
Thermal Analysis of an Oil Jet-Dry Sump Transmission Gear under Mixed-Elastohydrodynamic Conditions
}

\author{
E. Fatourehchi, H. Shahmohamadi, M. Mohammadpour*, \\ R. Rahmani, S. Theodossiades and H. Rahnejat \\ Wolfson School of Mechanical, Electrical and Manufacturing Engineering, Loughborough \\ University, Loughborough, UK \\ *M.Mohammad-pour@lboro.ac.uk
}

\begin{abstract}
Improved fuel efficiency and reduced emissions are key drivers for modern drivetrain systems. Therefore, in recent years, dry sumps with air-oil mist lubrication have been used for efficient transmission design in order to reduce the churning losses. With dry sumps appropriate cooling measures should be implemented to dissipate the generated contact heat in an efficient manner.

This paper integrates a tribological model with three dimensional thermofluid analysis in order to predict the heat generated in the lubricated meshing gear contacts and its dissipation rate by an impinging oil jet in air-oil mist environment. Such an approach has not hitherto been reported in literature. The results show that the generated heat under realistic conditions cannot be entirely dissipated by the impinging oil jet in the air-oil mist transmission casing. Numerical results are used to derive extrapolated regressed equations for heat transfer purposes for time-efficient analysis. These conform well with the detailed numerical results.
\end{abstract}

Keywords: Dry sump transmission, thermo-elastohydrodynamics, heat transfer, oil jet

\section{Nomenclature:}

$\boldsymbol{A}$

$A_{a}$

A

B
Apparent contact area

Asperity contact area

Hertzian semi-minor

half-width

Hertzian semi-major

half-width 
Specific heat capacity of solid surfaces

$D_{\text {nozzle }}$

$D_{\text {pitch }}$

$E_{r}$

$\boldsymbol{E}^{\prime}$

$\boldsymbol{f}_{\mathrm{v}}$

$f_{b}$

$\boldsymbol{h}_{c 0}^{*}$

$\boldsymbol{h}_{c 0}$

$\boldsymbol{k}^{*}$

$\boldsymbol{K}^{\prime}$

m

$\bar{p}$

$p$

$\boldsymbol{P}_{m}$

$\boldsymbol{R e}_{G}$

$R e_{j}$

$R_{z x}$

$R_{z y}$
Nozzle diameter

Pitch diameter

Reduced (effective)

elastic modulus

$\left(2 \mathrm{E}_{\mathrm{r}}\right) / \pi$

Viscous friction

Boundary friction

Dimensionless

central film thickness

Central film thickness

Lubricant

conductivity

Thermal conductivity

of solids

Module

Average contact

pressure

Pressure

Mean pressure of asperities

Reynolds number of the gear

Reynolds number of the jet

Principal equivalent radius of curvature along the direction of entraining motion, $x$

Principal equivalent radius of curvature along the direction of 
side leakage

$T$

Friction per unit

length

$\boldsymbol{U}_{\boldsymbol{j}} \quad$ Jet velocity

$\boldsymbol{U}_{\boldsymbol{r}} \quad$ Speed of entraining

motion of lubricant

(average surface

speed of surfaces)

$\boldsymbol{U}_{\mathbf{s}} \quad$ Sliding velocity of contact (relative

speed of surfaces)

$\vec{V} \quad$ Velocity vector

w Normal applied load

$W_{a} \quad$ Asperity contact load

$\boldsymbol{Z} \quad$ Number of teeth

\section{Greek symbols:}

$\alpha$

$\boldsymbol{\beta}$

$\boldsymbol{\varepsilon}$

$\varepsilon^{*}$

$\boldsymbol{\eta}$

$\eta_{0}$

$\boldsymbol{\theta}_{0}$

$\boldsymbol{\theta}_{\mathrm{s}}$
Pressure viscosity

coefficient

Average asperity tip

radius

Turbulence

dissipation rate

Pressure-induced shear coefficient

Lubricant dynamic viscosity

Lubricant dynamic viscosity at atmospheric pressure

Bulk temperature

Instantaneous surface temperature 


$\begin{array}{ll}\boldsymbol{\lambda} & \begin{array}{l}\text { Stribeck's oil film } \\ \text { parameter }\end{array} \\ \boldsymbol{\xi} & \text { Friction coefficient } \\ \boldsymbol{\rho} & \begin{array}{l}\text { Asperity density per } \\ \text { unit area }\end{array} \\ \boldsymbol{\rho}^{\prime} & \text { Density of lubricant } \\ \boldsymbol{\sigma} & \text { Density of solid } \\ \overline{\boldsymbol{\tau}} & \begin{array}{l}\text { Composite RMS } \\ \text { surface roughness }\end{array} \\ \boldsymbol{\tau}_{\boldsymbol{0}} & \begin{array}{l}\text { Average viscous } \\ \text { shear stress }\end{array} \\ \boldsymbol{\tau}_{L} & \text { Eyring stress } \\ \boldsymbol{\omega} & \text { Limiting shear stress } \\ & \text { Gear rotational speed }\end{array}$
Abbreviations:
EHL
Elastohydrodynamic
Lubrication
TCA
Tooth Contact
Analysis
VOF
Volume of fluid

\section{Introduction}

Reduced environmental impact and higher energy efficiency are key drivers for the modern drivetrain industry. Power losses of transmission systems, including those originating from gears, bearings and other components may be categorised as load-dependent or loadindependent losses. Friction-induced power loss is load-dependent and is as the result of generated friction in gear meshing, as well as from bearings. Various numerical and experimental studies have investigated the load-dependent power losses [1-6]. Li and Kahraman [1] developed a numerical model to predict frictional losses of spur gear pairs. Their model used mixed elastohydrodynamic lubrication (EHL), predicting the instantaneous 
gear pair mechanical power losses for each contacting teeth, as well as the overall losses during the gear meshing cycle. Mohammadpour et al. [2, 3] presented an integrated multibody dynamics and lubricated contact mechanics model for transient response of transmission efficiency, as well as noise, vibration and harshness (NVH) performance of hypoid gears under various conditions. They showed that the NVH performance and transmission efficiency are inextricably linked, sometimes with contradictory requirements. $\mathrm{NVH}$ performance deteriorates during acceleration, whereas it increases the chance of lubricant film formation, thus improving transmission efficiency. Talbot et al. [4] performed an experimental study of power loss of planetary gear set under various operating speeds and torques, inlet oil temperature, number of planets and roughness of the contacting surfaces. Their experimental results indicated that mechanical power loss decreases with reducing lubricant temperature and with improved surface quality. Mohammadpour et al. [5] extended the hypoid gear meshing problem to non-Newtonian shear of thin lubricant films under mixed-elastohydrodynamic conditions at very high loads, typical of vehicular differential systems. Fatourehchi et al. [6] introduced an analytical method with improved computation times to estimate gear contact power loss in high performance transmission systems. They investigated the effect of different gear teeth form modifications on power loss and system durability. Paouris et al. [7] extended the work in [2] through inclusion of sub-surface stress analysis and included the prediction of orthogonal reversing shear stresses, which are often responsible for inelastic deformation of contacting surfaces through fatigue spalling [8].

The load-independent power losses are due to churning and windage. They are mainly affected by the drag of lubricant on the rotating bodies. Therefore, these losses are influenced by lubrication cooling. Majority of transmission systems, particularly in automotive applications are cooled through a dipped (splash) lubrication system, where rotating gears are partially immersed into an oil sump. In such systems, the churning losses are one of the main concerns. Seetharaman and Kahraman [9] proposed a numerical model to predict the churning losses of gear pairs. The model took into account both spin power losses due to the interaction of individual gears with a bath of lubricant, as well as power loss due to the pumping of the lubricant into the gear mesh. The proposed model was validated through experimental measurements [10]. Changenet and Velex [11] established an analytical formulation to predict churning losses of a spinning gear. They investigated the effect of various gear ratios on the churning losses. 
Windage power loss is another source of load-independent losses. Dawson [12] carried out experimental measurements on gear windage losses. However, the experiments were carried out in air, thus not accounting for any lubricant vapour and mist.

Recently, dry sump (no oil bath) lubrication has received much attention. It has been implemented in many high-performance transmissions in an attempt to minimise/eliminate the churning losses. In these cases, oil jets provide lubricant feed into the gear meshing conjunctions to dissipate the generated contact heat. In dry sump gearboxes, it is necessary to ensure that a sufficient volume of lubricant penetrates into the meshing teeth conjunctions for lubrication and cooling. Gear bulk temperature is a controlling factor in inhibiting gear scoring or scuffing failures [13]. Therefore, proper cooling prevents excessive surface temperature rise, which would lead to the failure of the gear teeth. Due to the limited application of this type of lubrication (mostly in the aerospace industry), there have been few studies reported in the open literature with regard to the modelling of jet lubrication and prediction of performance. Those presented are mostly concerned with surface oil availability and penetration depth into the gear teeth conjunctions using an impinging oil jet [13, 14]. Akin et al. [14] performed several experimental tests for oil jet lubrication of spur gears. The tests were carried out on different gears with a variable oil jet velocity. They used a highspeed camera to determine the oil impingement depth. Their study concluded that if the jet is not atomized an optimum oil penetration depth could be attained. The study did not tackle the thermal behaviour of jet impingement on rotating gear surfaces. McCain and Alsandor [15] introduced an analytical method to study the effect of oil jet nozzle position and oil impingement depth on the load carrying capacity of the lubricant film. Their analysis indicated that modified gear teeth (tip relief) would improve the lubricant penetration. They also claimed that improved oil jet lubrication is achievable if the jet would impinge upon both the loaded and unloaded gear teeth faces. This is directly due to the oil jet position and velocity. However, their model did not take into account the windage losses. DeWinter and Blok [16] developed an analytical model to determine the heat removal rate of an impinging jet from gear surfaces. The model was based on a surface-adhered laminar film layer formed on the gear flanks, which over-estimated the thickness of the layer. This over-estimation led to the over-estimation of the rate of heat dissipation.

Recently, Fondelli et al. [17] studied the oil injection losses on a rotating gear through a computational fluid dynamics (CFD) analysis. Their model was based on a single oil jet impingement on a high-speed gear, using the volume of fluid (VOF) model. The analysis was 
carried out to obtain the resistive torque due to oil jet lubrication. Based on their results, the impinging oil jet breaks up into small droplets, which do not play a role in the actual lubrication process. The study did not include a heat dissipation analysis, which is important in impinging oil jet losses.

The current study reports on an integrated numerical model to obtain conjunctional heat generation in lubricated gear contacts, with heat dissipation due to an impinging oil jet in the air-oil mist environment of a dry sump transmission. This approach, has not hitherto been reported in literature.

In order to obtain an efficient analytical model for future system-level studies, the effect of different variables including nozzle oil flow rate, oil availability in transmission housing, gear rotational speed and temperature on the overall heat dissipation from the gear surface is investigated. An extrapolated equation is derived from all the predicted numerical results, using linear regression analysis. The presented equations would enable transmission designers to analyse the heat dissipation performance of dry sump transmissions without the need for further time-consuming numerical analysis.

\section{Methodology}

The presented method combines a lubricated contact mechanics model (tribological model) with thermo-fluid dynamics (CFD model) of an impinging jet of supplied lubricant to the gear contact in an air-oil mist environment (dry sump) of a high-performance transmission system. The contact model predicts the generated heat in the meshing teeth conjunctions, whilst the thermo-fluid analysis deals with the issue of gear pair cooling.

\subsection{Tribological model}

The heat generated in the contacts of meshing teeth pairs is as the result of friction. The meshing gear teeth pairs are subject to mixed-elastohydrodynamic regime of lubrication because of the shear of thin lubricant films and asperity interactions of real rough teeth flanks. To determine these sources of friction, the instantaneous contact geometry and kinematics, comprising rolling and sliding surface velocities, as well as the instantaneous applied normal load during the meshing cycle are required. These parameters constitute the required input for the elastohydrodynamic analysis, and are obtained through the use of Tooth 
Contact Analysis (TCA), based on finite element approach highlighted by Vijayakar [18], Xu and Kahraman [19] and Karagiannis et al. [20]. The developed TCA model takes into account different tooth profile modifications to obtain accurate contact geometry, contact kinematics and loading.

\section{(a)- Viscous friction}

Evans and Johnson [21] developed an analytical method to obtain viscous friction in elastohydrodynamic contacts. These relationships are based upon an experimentally validated analytical approach. They take into account the thermal shear thinning of the lubricant under various regimes of traction; in Newtonian as well as non-Newtonian shear behaviour of the lubricant. This equation predicts the maximum shear stress and friction. It is used in the current analysis in order to obtain the worst-case scenario. In the derivation of this equation, the effect of temperature on viscosity was taken into account with thermal analysis, based on the work of Crook [22]. Later in the results section (4-e), where the effect of gear surface temperature in a jet and air-oil mist system is studied, a range of power losses due to viscous friction are studied.

The coefficient of friction is given as [21]:

$\mu=0.87 \alpha \tau_{0}+1.74 \frac{\tau_{0}}{\bar{p}} \ln \left[\frac{1.2}{\tau_{0} h_{c 0}}\left(\frac{2 K^{*} \eta_{0}}{1+9.6 \xi}\right)^{\frac{1}{2}}\right]$

where:

$\xi=\frac{4}{\pi} \frac{K^{*}}{h_{c 0} / R_{z x}}\left(\frac{\bar{p}}{E^{\prime} R_{z x} K^{\prime} \rho^{\prime} c^{\prime} U_{r}}\right)^{1 / 2}$

where, $h_{c 0}$ is the film thickness at any instant of time during the meshing cycle under the operating conditions. This is obtained using the lubricant film thickness equation provided by Chittenden et al. [23]:

$h_{c 0}^{*}=4.31 U_{e}^{0.68} G_{e}^{0.49} W_{e}^{-0.073}\left\{1-e^{\left[-1.23\left(\frac{R_{z y}}{R_{z x}}\right)^{2 / 3}\right]}\right\}$

where, $R_{z x}$ and $R_{z y}$ are the equivalent instantaneous principal radii of contact of a pair of meshing teeth at the point of contact within the meshing cycle [2,5]. The operational conditions of the studied case are within the range of validity of both equations (1) and (2). 
It should be noted that the above film thickness formula does not take into account any lubricant non-Newtonian shear behaviour. According to Mohammadpour et al. [5], the largest difference between Newtonian and non-Newtonian film thickness is around10\%. Therefore, the effect of non-Newtonian shear is rather inappreciable when calculating viscous friction (equation (1)) under high non-Newtonian shear. The non-dimensional groups are:

$U_{e}=\frac{\pi \eta_{0} U_{r}}{4 E_{r} R_{z x}}, W_{e}=\frac{\pi W}{2 E_{r} R_{z x}^{2}}, G_{e}=\frac{2}{\pi}\left(E_{r} \alpha\right), h_{c 0}^{*}=\frac{h_{\mathrm{c} 0}}{R_{z x}}$

where, the pressure viscosity coefficient, $\alpha$, is assumed to remain constant. In practice, the value of $\alpha$ alters with temperature. The same value is also used in the relationship for the coefficient of friction (equation (1)).

The effect of pressure on viscosity is based on the Roelands' equation [4], which was used in the numerical analysis of Chittenden et al. [23], thus embedded in equation (2). The lubricant density varies with pressure according to Dowson and Higginson [24] as:

$\rho=\rho_{0}\left(1+\frac{0.58 P E^{\prime}}{1+1.68 P E^{\prime}}\right)$

The effect of temperature on lubricant density is not included in the above equation since the lubricant temperature rise in the case studied is utmost $13^{\circ} \mathrm{C}$, as shown in the results section.

Therefore, the generated viscous friction becomes:

$f_{v}=\mu W$

\section{(b)- Boundary friction}

Lubricant films in gear teeth pair contacts are usually quite thin; comparable to the roughness of the contiguous surfaces. Therefore, interaction of the opposing asperity peaks on the counter face surfaces occurs and promotes boundary friction. Greenwood and Tripp [25] presented a model that is widely used in predicting boundary friction. Mixed regimes of lubrication occur when the Stribeck's oil film parameter falls within the range: $1<\lambda=\frac{h_{c 0}}{\sigma}<$ 2.5. Under these conditions, a proportion of the contact load is carried by the contact of asperity heights as:

$W_{a}=\frac{16 \sqrt{2}}{15} \pi(\xi \beta \sigma)^{2} \sqrt{\frac{\sigma}{\beta}} E^{\prime} A F_{5 / 2}(\lambda)$

where, the statistical function $F_{5 / 2}(\lambda)$ for an assumed Gaussian distribution of asperities is obtained as [26]: 
$F_{5 / 2}= \begin{cases}-0.004 \lambda^{5}-0.057 \lambda^{4}-0.29 \lambda^{3}-0.784 \lambda^{2}-0.784 \lambda-0.617 & \text { for } \lambda<2.5 \\ 0 ; & \text { for } \lambda \geq 2.5\end{cases}$

For steel surfaces, the roughness parameter $(\xi \beta \sigma)$ is generally in the range $0.03-0.07$ [25]. $\sigma / \beta$ is a measure of the average asperity slope [27]. This is usually in the range: $10^{-4}-10^{-2}$. In the current study, these were obtained through measurements of a typical gear tooth topography using white light interferometry as: $\xi \beta \sigma=0.055$ and $\sigma / \beta=10^{-3}[28]$.

A thin film of boundary active lubricant additives (a tribo-film) is usually adsorbed or bonded to the summit of the interacting asperities, or is entrapped in their inter-spatial valleys. It is assumed that the boundary film is functioning ideally during gear meshing. In practice the temperature rise of the surface as well as potential wear can affect the tribo-film, thus leading to changes in boundary friction. This lubricant film is subjected to non-Newtonian shear, thus:

$f_{b}=\tau_{L} A_{a}$

where $\tau_{L}$ is the lubricant's limiting shear stress:

$\tau_{L}=\tau_{0}+\varepsilon^{*} P_{m}$

where, the mean asperity interaction pressure $P_{m}$ is obtained as:

$P_{m}=\frac{W_{a}}{A_{a}}$

The asperity contact area is given as [25]:

$A_{a}=\pi^{2}(\xi \beta \sigma)^{2} A F_{2}(\lambda)$

The statistical function $F_{2}(\lambda)$ is calculated as [26]:

$F_{2}(\lambda)=\left\{\begin{array}{lr}-0.002 \lambda^{5}-0.028 \lambda^{4}-0.173 \lambda^{3}+0.526 \lambda^{2}-0.804 \lambda-0.500 & \text { for } \lambda<2.5 \\ 0 ; & \text { for } \lambda \geq 2.5\end{array}\right.$

\section{(c)- Power Loss}

The instantaneous power loss within the meshing cycle is obtained as:

$P_{\text {loss }}=\left(f_{v}+f_{b}\right) U_{s}$

It is assumed that the total generated power loss would convert to heat. The thin elastohydrodynamic films contribute very little to the transfer of generated heat from the 
contact conjunction through convection cooling [27]. Therefore, it is safe to assume that the generated heat is mainly conducted through the contacting teeth, thus increasing their surface temperatures. Some of the generated heat is then dissipated by an oil jet directed towards the contacting teeth, as well as by the air-oil mist environment of the dry sump transmission casing in order to maintain the thermal balance under steady state conditions. The increased surface temperature is the heat source in the computational fluid dynamics model. The boundary conditions should be estimated through use of the integrated tribological model. The contact of a pair of cylindrical spur gear teeth yields a finite line contact of thin rectangular band of width $2 b[27,28]$. Friction per unit length is then obtained as:

$T=\frac{f_{v}+f_{b}}{2 b}$

Therefore, the heat generated due to the power loss per unit length of contact becomes $T U_{s}$. Assuming that the heat flows equally to both the contacting surfaces, Crook [22] showed that the average surface temperature rise would become:

$\theta_{S}=\theta_{0}+\frac{0.5 T U_{S}}{\left(\pi K^{\prime} \rho^{\prime} c^{\prime} a U_{r}\right)^{1 / 2}}$

\subsection{Thermo-fluid dynamics of an Impinging Jet}

A standard k- $\varepsilon$ computational fluid dynamics (CFD) model is used to model the impinging turbulent lubricant flow. The governing equations for conservation of mass and momenta for each phase in a 3D Newtonian and incompressible turbulent flow are obtained as [29]:

Continuity condition:

$\frac{\partial u_{i}}{\partial x_{i}}=0$

Conservation of momentum:

$\rho \frac{\partial\left(u_{i} u_{j}\right)}{\partial x_{j}}=-\frac{\partial p}{\partial x_{i}}+\frac{\partial}{\partial x_{j}}\left[\eta_{\text {eff }}\left\{\frac{\partial u_{i}}{\partial x_{j}}+\frac{\partial u_{j}}{\partial x_{i}}\right\}\right]$

Turbulent kinetic energy:

$\rho \frac{\partial}{\partial x_{j}}\left(u_{j} k-\frac{\eta_{\mathrm{eff}}}{\sigma_{k}^{\prime}} \times \frac{\partial k}{\partial x_{j}}\right)=G-\rho \varepsilon$

Dissipation rate of $k$ : 
$\rho \frac{\partial\left(u_{j} \varepsilon\right)}{\partial x_{j}}=\frac{\partial}{\partial x_{j}}\left(\frac{\eta_{\mathrm{eff}}}{\sigma_{\varepsilon}^{\prime}} \times \frac{\partial \varepsilon}{\partial x_{j}}\right)+\frac{\left(C_{1} G \varepsilon-C_{2} \rho \varepsilon^{2}\right)}{k}$

where:

$G=\eta_{\mathrm{t}} \frac{\partial u_{j}}{\partial x_{i}}\left(\frac{\partial u_{j}}{\partial x_{i}}+\frac{\partial u_{i}}{\partial x_{j}}\right)$

and the effective lubricant viscosity is:

$\eta_{\mathrm{eff}}=\eta+\rho C_{\eta} \frac{k^{2}}{\varepsilon}$

The constants in the above set of equations have nominal values provided by Launder and Spalding [30] as:

$\mathrm{C}_{1}=1.44, \mathrm{C}_{2}=1.92, \mathrm{C}_{\eta}=0.09, \sigma_{k}^{\prime}=1.00$ and $\sigma_{\varepsilon}^{\prime}=1.30$

The energy equation is [31]:

$\rho \frac{D H}{D t}=\frac{D p}{D t}+\nabla \cdot\left(k^{*} \nabla \theta\right)+\bar{\tau}_{i j} \frac{\partial U_{i}}{\partial x_{j}}$

where, $H$ is the fluid enthalpy, $\theta$ is the temperature and $K^{*}$ is the lubricant thermal conductivity.

It should be noted that in the developed CFD model, the Nusselt number is coupled with Reynolds number, based on the Dittus-Boelter equation [32].

\section{(a)- Volume of fluid (VOF) model}

The interface between the immiscible liquid lubricant and the liberated vapour phase is monitored using the volume of fluid (VOF) method [33]. A volume fraction function $(\Omega)$ is used as an indicator of the two fluid phases. The interface between the phases is obtained through solution of the convection equation:

$\frac{\partial \Omega}{\partial t}+\vec{V} \cdot \nabla \Omega=0$

The surface tension model is the continuum surface force (CSF) model proposed by Brackbill et al. [34]. With this model, the interfacial tension is calculated and added to the source term in the momentum equation (16). Based on the VOF function, the interface unit normal ( $\hat{\mathrm{n}}$ ) and the curvature $(K)$ are calculated as: 
$\widehat{\mathrm{n}}=\frac{\nabla \Omega}{|\nabla \Omega|} \quad$ and $\quad K=-(\nabla \cdot \hat{\mathrm{n}})$

Hence, the force source $(\vec{F})$ in the momentum equation is expressed as:

$\vec{F}=\bar{\sigma} K \frac{\nabla \Omega}{|\nabla \Omega|}$

where, $\bar{\sigma}$ is the interfacial surface tension between the liquid lubricant and the vapour phase. Based on the governing equation, the interfacial tension between the lubricant and vapour phases and their viscosities are taken into account in the analysis.

\section{(b)- Model configuration}

Figure 1 is a schematic representation of the developed model, including the boundary conditions for each face of a gear blank in plan and side view elevations. The oil jet is usually directed towards the contact exit of a pair of meshing teeth for better heat dissipation for a single gear pair only. Hence, the effect of the impinging oil jet on a single gear body can be examined, when it is assumed to have received half the generated contact heat. 


\section{Front view}

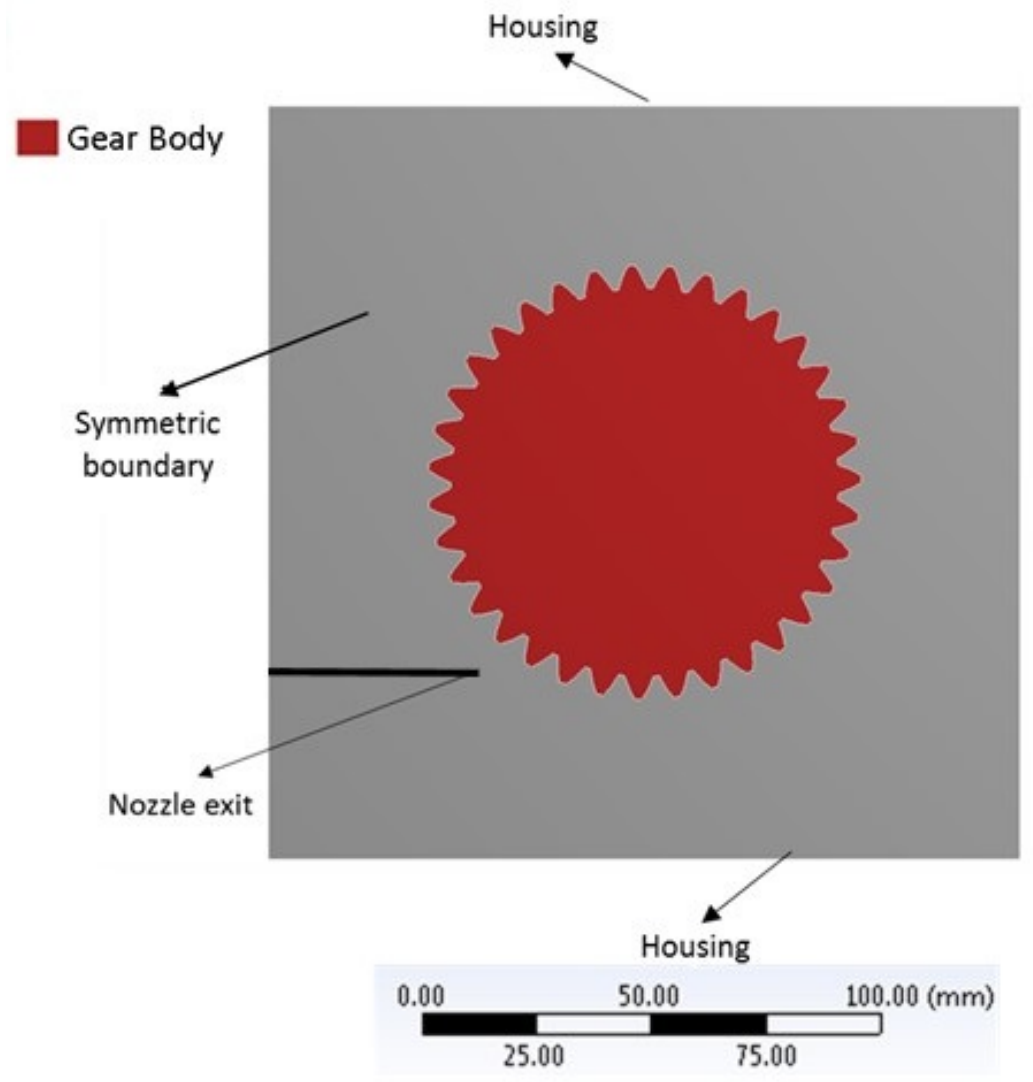

Side view

Pressure outlet

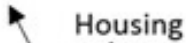

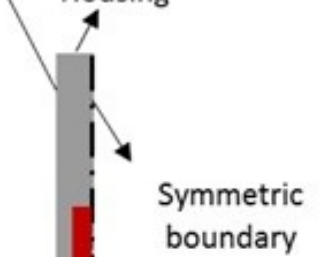

Symmetric boundary

Figure 1: Schematic representation of the developed model

To reduce the computation time and memory requirements, symmetric boundary conditions are assumed through the middle of the tooth flank as shown on the right-hand side of Figure 1. Furthermore, the effect of surface roughness is not taken into account in the CFD model since the roughness of the gear surface is less than $1 \mu \mathrm{m}$, which would not affect macro level oil flow determined through CFD on the rotating gear surface.

The aim is to study the heat dissipation as determined by a heat transfer coefficient. Since the volume fraction of the liquid lubricant is much higher for the gear teeth directly facing the impinging jet, an average value for the heat transfer coefficient is obtained for such teeth separately from the others (figure 2). The heat dissipation from the rest of the gear body is determined separately. 


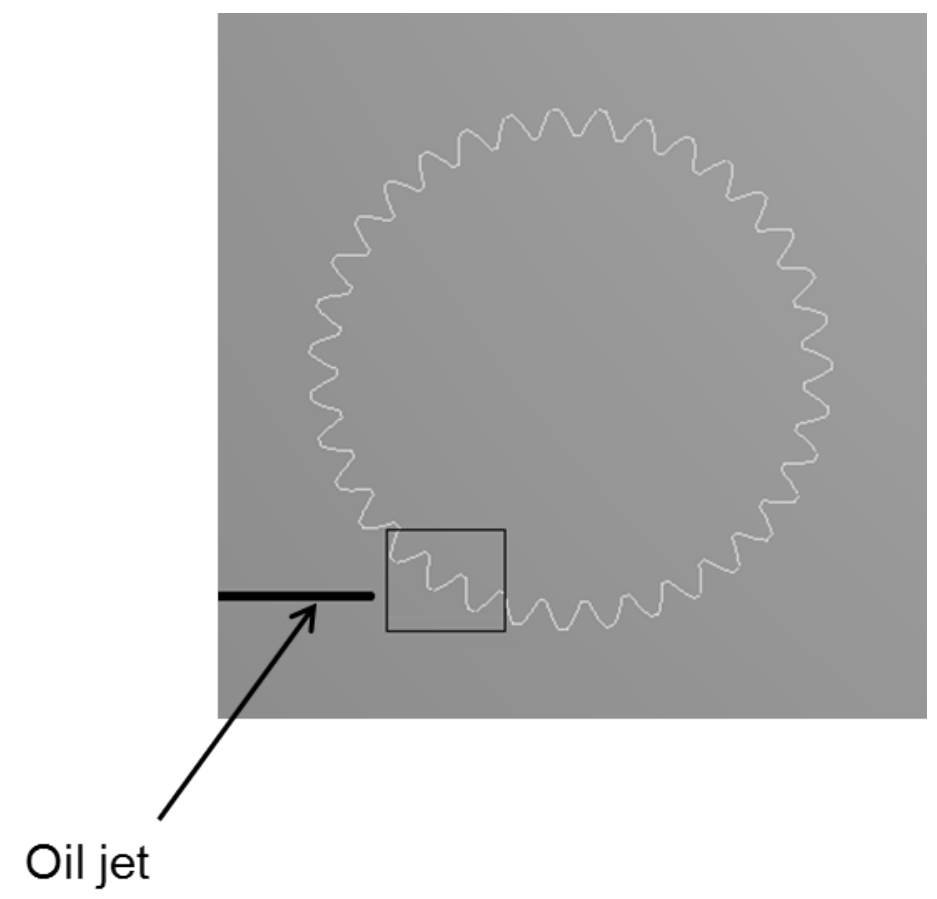

Figure 2: Schematics of specified teeth sections facing the impinging jet

\section{(c)- Boundary conditions}

To define the boundaries of the computational domain, it is assumed that the gear rotates at a steady speed in a sufficiently large box (Figure 1). This is to minimise the effect of the computational boundary upon the predictions. The gear flank temperature is assumed to remain unchanged under steady-state conditions. This is calculated by the methodology highlighted in the previous section. The nozzle exit is defined as the lubricant inlet mass flow with a given mass flow rate. The mass flow rate for the baseline model is $0.0168 \mathrm{~kg} / \mathrm{s}$ at $100^{\circ} \mathrm{C}$. The average lubricant temperature at the exit of the nozzle and the gear flank temperature are considered to be the same as that of the housing temperature, which is constant at $107^{\circ} \mathrm{C}$, under steady state thermal balance. Atmospheric pressure is specified as the outlet boundary condition of the transmission casing (computational domain).

For the specified speed of $114 \mathrm{rad} / \mathrm{s}$, the time step size is chosen to be $10^{-4} \mathrm{~s}$. Considering 35 gear teeth, this provides almost 15 time steps of analysis for a tooth traverse through the impinging jet. 


\section{Solution procedure}

The proposed methodology integrates a tribological model of heat generation with CFD simulations to study the influence of different parameters on a combined oil jet and air-oil mist lubrication system.

The solution procedure is:

Step 1: For a given gear pair speed and torque, the instantaneous contact geometry, rolling and sliding velocities and the normal contact load variations are obtained through TCA.

Step 2: The TCA results yield the inputs for the mixed-elastohydrodynamic lubrication contact model. This model predicts viscous and boundary friction contributions, the instantaneous power loss and the generated surface temperature rise in a meshing cycle.

Step 3: The temperature rise is an input to the developed 3D CFD model in order to calculate the quantity of heat conducted to the gear surfaces for different combinations of jet and air-oil mist lubricant cooling.

It should be noted that a range of parameters, including the surface flash temperature are taken into account. Thus, the calculated surface temperature only provides the baseline (mid value) for certain working conditions.

In order to solve the system of equations in the CFD model, the commercial CFD package Fluent 16.2 (ANSYS Inc.) based on the finite volume method is used [35]. A 3D CFD model is developed to ascertain the effect of different parameters in a combined oil jet and air-oil mist lubrication system. The CFD analysis is carried out using a pressure-based VOF model. Coupled algorithm is selected to treat the velocity-pressure coupling. The flow is computed by a standard $k-\varepsilon$ turbulent flow model. The properties of fluid in both phases are considered as the input data. In the VOF multi-phase model an interface is considered between the phases as a boundary. Therefore, there is no need to calculate the properties of the mixture, which is an advantage of the mixture model.

\section{Results and discussion}

For the purpose of analysis, a dry sump transmission system of a C-segment vehicle is considered. Different combinations of jet and air-oil mist lubrication systems are analysed to 
determine the quantity of heat dissipated from the gear surfaces. Tables 1 and 2 provide the lubricant and gear properties. All the input data are measured

Table 1: Lubricant and solid properties

\begin{tabular}{|c|c|}
\hline Pressure viscosity coefficient $\left(\mathrm{Pa}^{-1}\right)$ & $2.383 \times 10^{-8}$ \\
\hline Lubricant Atmospheric dynamic viscosity at $100^{\circ} \mathrm{C}(\mathrm{Pa} . \mathrm{s})$ & 0.0171 \\
\hline Lubricant Eyring stress (MPa) & 2 \\
\hline Thermal conductivity of fluid $(\mathrm{W} / \mathrm{mK})$ & 0.2 \\
\hline Heat capacity of fluid $(\mathrm{J} / \mathrm{kg} \mathrm{K})$ & 1400 \\
\hline Density of lubricant fluid at $100^{\circ} \mathrm{C}\left(\mathrm{kg} / \mathrm{m}^{3}\right)$ & 829.3 \\
\hline Pressure-induced shear coefficient & 0.047 \\
\hline Modulus of elasticity of contacting solid $(\mathrm{GPa})$ & 199.9 \\
\hline Poisson's ratio of contacting solids $(-)$ & 0.3 \\
\hline Density of contacting solids $\left(\mathrm{kg} / \mathrm{m}^{3}\right)$ & 7850 \\
\hline Thermal conductivity of contacting solids $(\mathrm{W} / \mathrm{m} \mathrm{K})$ & 46.7 \\
\hline Heat capacity of contacting solids $(\mathrm{J} / \mathrm{kg} \mathrm{K})$ & 470 \\
\hline
\end{tabular}

Table 2: Gear geometry

\begin{tabular}{|c|c|}
\hline RMS composite Surface roughness $(\mu \mathrm{m})$ & 1 \\
\hline Module $(\mathrm{mm})$ & 3.8 \\
\hline Face width $(\mathrm{mm})$ & 13.5 \\
\hline Number of teeth (pinion:gear) & $13: 35$ \\
\hline Pitch diameter (pinion:gear) $(\mathrm{mm})$ & $44: 134$ \\
\hline Normal pressure angle $\left(^{\circ}\right)$ & 28 \\
\hline
\end{tabular}

A typical urban manoeuvre with vehicle speed of $30 \mathrm{~km} / \mathrm{h}$, corresponding to an accelerating point in the New European Drive Cycle (NEDC) [36] is chosen. The operational conditions measured in dynamometric tests or based on NEDC are included in Table 3.

Table 3: Operational conditions

\begin{tabular}{|l|l|}
\hline Parameter & Value \\
\hline $\begin{array}{l}\text { Power transmission from engine (W) - } \\
\text { Determined based on a NEDC manoeuvre }\end{array}$ & 1086 \\
\hline $\begin{array}{l}\text { Gear rotational speed (the baseline model) } \\
\text { (rad/s) - Determined based on a NEDC } \\
\text { manoeuvre }\end{array}$ & 114 \\
\hline $\begin{array}{l}\text { The oil mass flow rate at nozzle exit (kg/s)- } \\
\text { measured }\end{array}$ & 0.0168 \\
\hline \begin{tabular}{l} 
The oil temperature at nozzle exit $\left({ }^{\circ} \mathrm{C}\right)-$ \\
\hline
\end{tabular} & 100 \\
\hline
\end{tabular}


measured

The engine torque is calculated using the approach expounded by Norris et al. [37]. For these specified conditions, the gear rotational speed is set at $114 \mathrm{rad} / \mathrm{s}$. This working condition provides a baseline as a centre range of the parameters of interest in the current study. Subsequently, a range of parameters is defined, based on these baseline values.

Figure 3 shows the predicted frictional power loss in a meshing cycle for the chosen conditions.

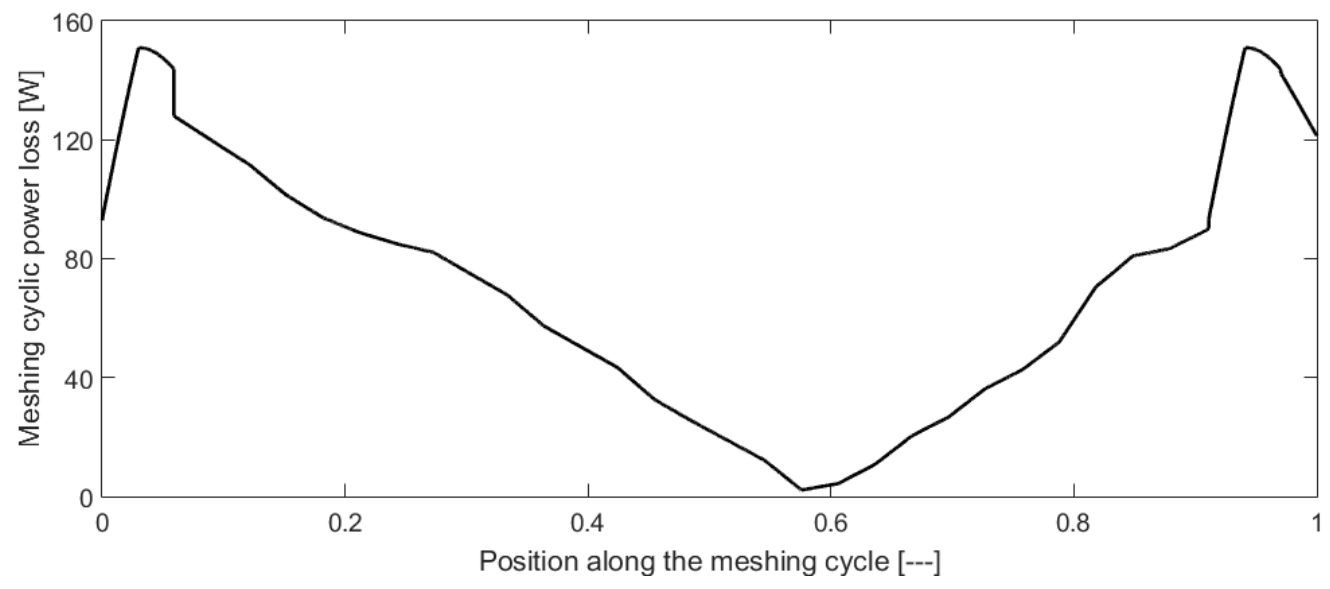

Figure 3: Frictional power loss

The average power loss for a meshing cycle in this case is $68 \mathrm{~W}$ with a gear surface temperature rise of $13^{\circ} \mathrm{C}$, where the transmitted power from engine to the transmission for this case is $1086 \mathrm{~W}$. According to Crook [22], the generated heat is conducted equally to the two mating gear teeth surfaces (i.e. $34 \mathrm{~W}$ per tooth flank in this case). Owing to the presence of a thin elastohydrodynamic lubricant film, any heat dissipation due to convection is neglected. The generated heat should be dissipated from the gear. The current study is confined to the determination of heat dissipation from a rotating gear with different oil jets in an air-oil mist environment. The study does not take into account other heat transfer mechanisms such as heat conduction through the gear blank and onto its supporting shafts and bearings. The conductive heat transfer has been found to be fairly inappreciable [38, 39].

As a measure, the average heat transfer coefficient is obtained for the gear teeth facing the impinging jet and for others away from this position (Figure 2), using the 3D CFD model. 
Then, the convective heat transfer between the impinging oil jet and the gear surface is calculated for both cases.

The heat transfer from a gear tooth facing the oil jet is obtained as:

$\dot{Q}_{1}=h_{1} A_{1} \Delta \theta_{1}$

where, $h_{1}$ is the average heat transfer coefficient for a tooth facing the impinging jet flow, $A_{1}$ is the area of the gear tooth and $\Delta \theta_{1}$ is its temperature rise. The temperature difference between the surface and the adherent free surface mixture layer in contact with the body is obtained based on a volumetric average as:

$\Delta \theta_{1}=\frac{V O F_{\text {oil }}\left(\theta_{\text {gear surface }} \theta_{\text {oil-nozzle exit }}\right)+V O F_{\text {air }}\left(\theta_{\text {gear surface }} \theta_{\text {surronding air }}\right)}{\left(\text { VOF }_{\text {oil }}+V O F_{\text {air }}\right)}$

The surrounding air temperature is assumed to be the same as that of the housing. The heat transfer from other gear teeth can be obtained as:

$\dot{Q}_{2}=h_{2} A_{2} \Delta \theta_{2}$

where, $h_{2}$ is the average heat transfer coefficient for all the gear teeth other than those directly facing the oil jet, $A_{2}$ is the area of these gear teeth and $\Delta \theta_{2}$ is the temperature difference between the gear surface and the surrounding air.

\section{(a)- Heat dissipation of impinging oil in a dry sump}

First, the heat dissipation from a gear flank through an impinging jet is studied. The gear rotational speed in the CFD model is $114 \mathrm{rad} / \mathrm{s}$. The oil jet operates with flow rate of 0.0168 $\mathrm{kg} / \mathrm{s}$. Using equations (25) and (27), the heat dissipation through the gear flank is obtained as $0.56 \mathrm{~W}$. This is quite small compared with the generated heat through contact friction.

DeWinter and Blok [16] developed an analytical method to obtain the total quantity of heat removed per unit width from the cooled tooth faces. The method was used by Townsend and Akin [40] to compare with experimental measurements. They indicated that this method overestimates the heat dissipation. This is due to the overestimation of the free-surface adherent lubricant layer on the gear flank. According to DeWinter and Blok [16] heat dissipation from a rotating gear through an impinging oil jet is: 
$Q_{t o t}=1.16\left(\frac{L}{m}\right)^{5 / 4} \cdot z^{-1 / 4} \cdot\left(\frac{v}{a^{\prime}}\right)^{1 / 4} \cdot \frac{m b^{\prime} \theta_{s}}{\omega^{1 / 2}}$

where, $a$, is the thermal diffusivity of oil [27]:

$a^{\prime}=\frac{k}{\rho c}$

and, $b$, is the thermal contact coefficient of oil [27]:

$b^{\prime}=(k \rho c)^{1 / 2}$

According to Akin et al. [41], the maximum oil jet penetration depth, $L$, is about $20 \%$ of the tooth flank depth. Using equations (28) - (30), the heat dissipation rate from a gear flank by an impinging oil jet in the current case study is, therefore, $1.69 \mathrm{~W}$. This value is higher than the estimation of the current CFD model, which is an expected outcome according to the experimental findings of Akin et al. [41] and the overestimation of equation (28). Nevertheless, both values are in the same range and much lower than the generated heat which is to be dissipated from meshing gears. It can be concluded that a single impinging jet (which is common in real engineering practice) with dry sumps is far less effective in removing the total generated heat. One reason for the small heat dissipation by the jet is that the impinging oil has insufficient time to remove the heat from the gear surface. Figure 4 shows the temperature contours based on the baseline operational values at the contact outlet, as well as isobaric temperature distribution of the rebounding jet. It shows that the rebounding flow temperature is hardly altered. 


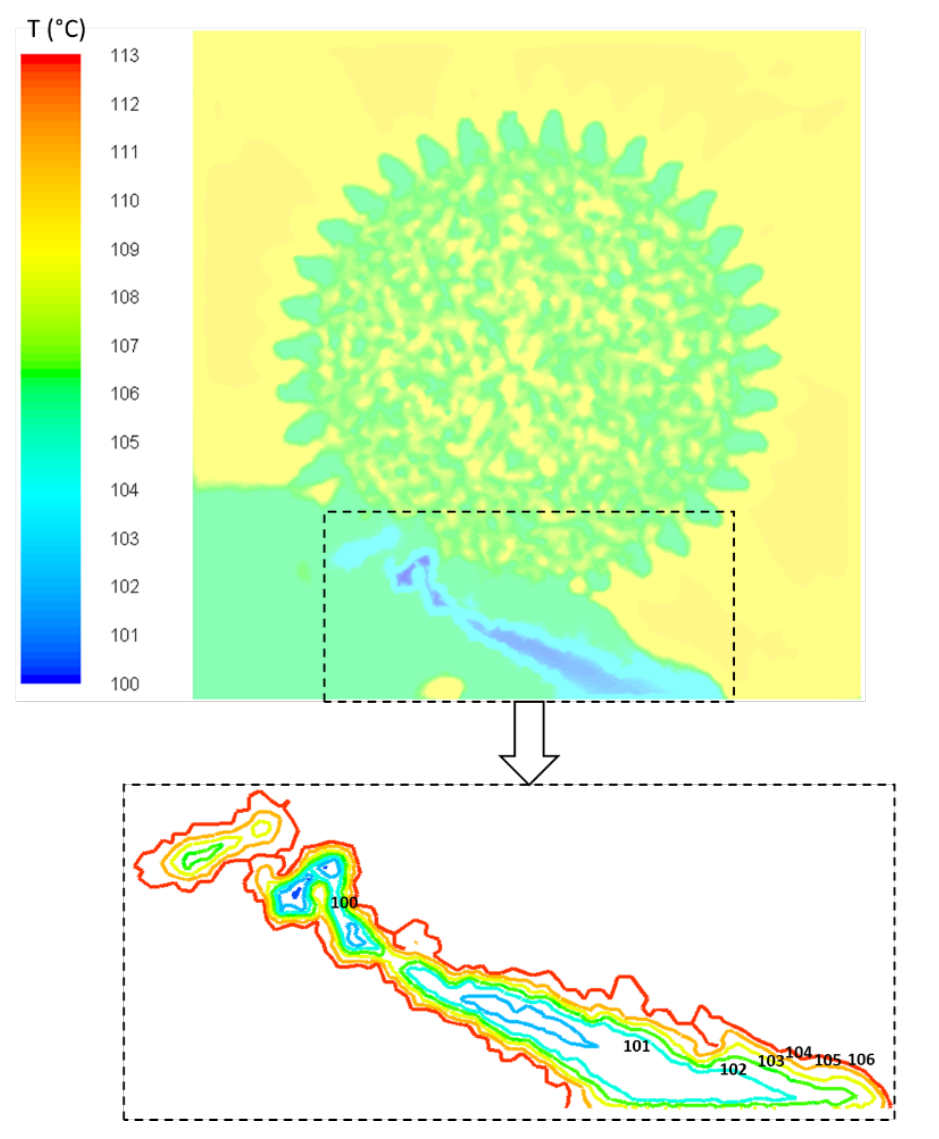

(a)

(b)

Figure 4: (a) Contours of temperature at the pressure outlet (b) Isobaric temperature distribution at the impinging jet area

Hence, other heat removing mechanisms should be examined in order to understand the thermal behaviour of the system. Clearly, much of the heat is transferred through the surface of the transmission casing, transmission shafts and bearings. However, the current study focuses on the estimation of heat dissipation by fluid flow only in a quest to reduce the quantity of lubricant in a dry sump arrangement. Therefore, it is necessary to investigate other mechanisms of air-oil mist cooling.

In order to investigate the multi-phase flow, the following figures show contours of oil volume fraction, mixture pressure and velocity at the outlet boundary. The simulation is based on the baseline operational values.

Figure 5 shows the oil volume fraction. 


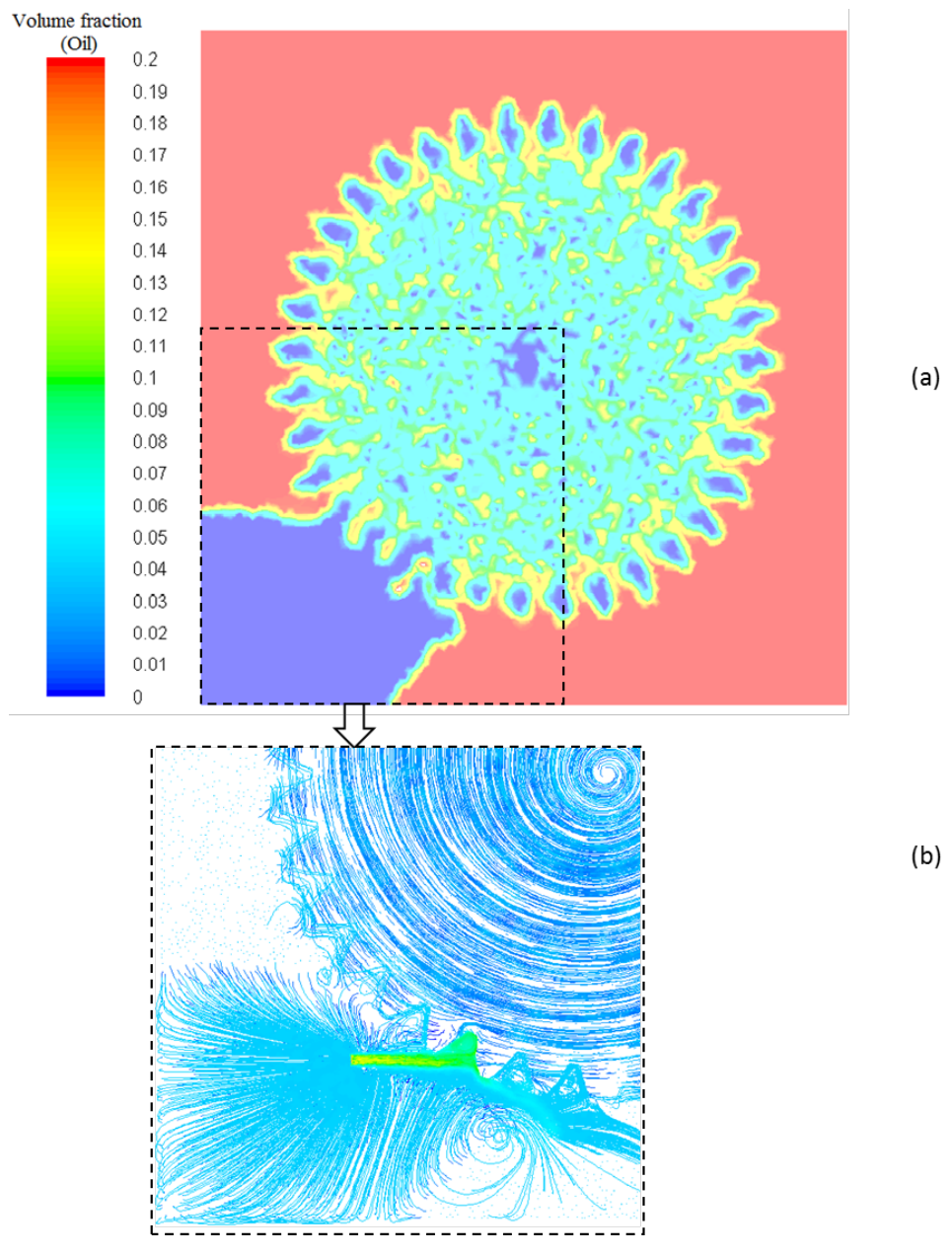

Figure 5: (a) Contours of oil volume fraction at outlet boundary, and (b) Oil flow path-lines at in the impinging jet region

Figure 5-a shows that the oil volume fraction remains almost unaltered as an input (i.e. 0.2 based on the baseline operational value) for areas which are not close to the rotating gear and the impinging jet, therefore remain unaffected by their momenta. However, the area around the rotating gear contains a reduced volume of lubricant. This is more pronounced around the impinging oil jet due to the momenta of the rotating gear and the impinging jet, causing the lubricant to follow the path-lines shown in figure 5-b.

Figure 6 shows the absolute pressure of the air-oil mist environment. 


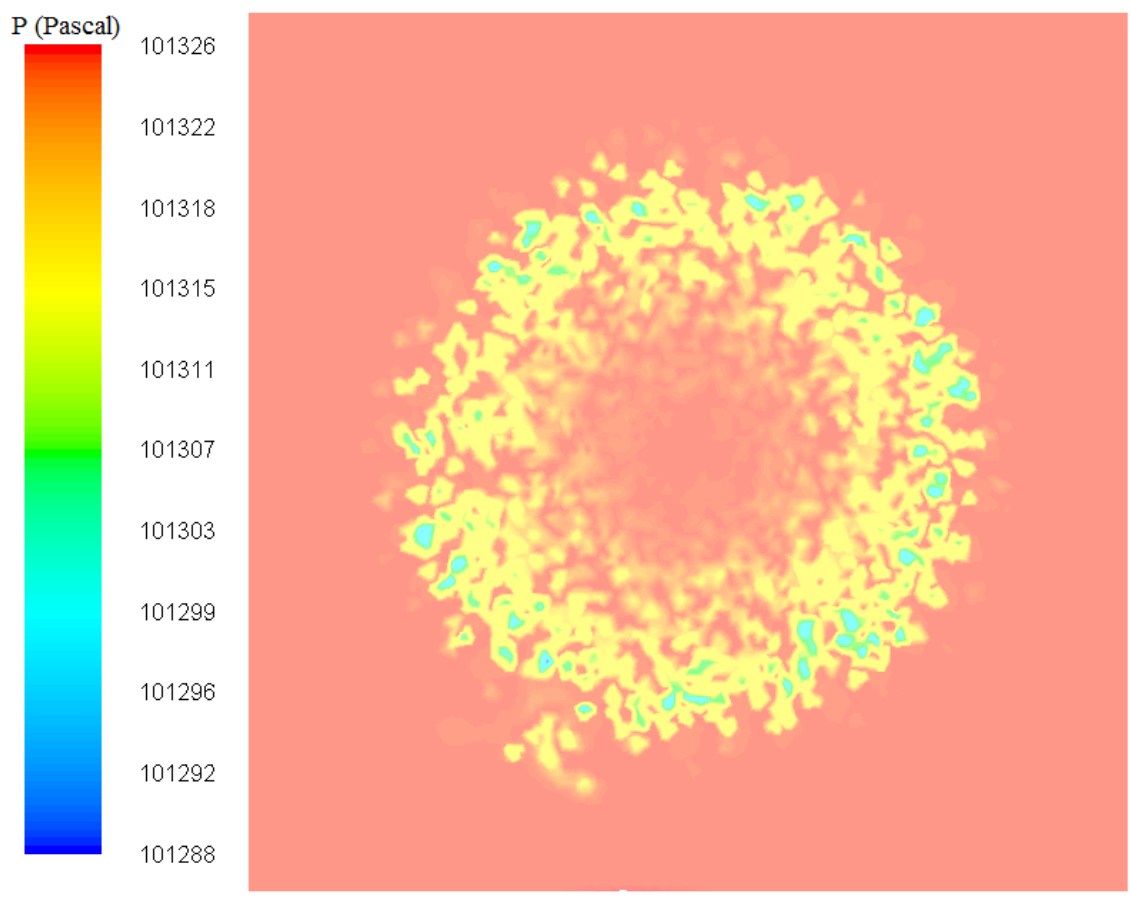

Figure 6: Contours of pressure at the outlet boundaries

The mixture pressure is sub-atmospheric due to vortex flows within the gear teeth involute as well as in the flow vortex around the impinging jet. The presence of sub-ambient pressures at the conjunctional outlet indicates the presence of vapour which aids cooling. If the impinging jet targeted the inlet to the conjunction, the presence of vapour would cause contact starvation. The presence of sub-ambient pressures around the impinging jet vortex flow is often a cause of nozzle erosion, a problem encountered in practice.

Figure 7 shows the corresponding contours of velocity around the rotating gear blank and the impinging oil jet. 

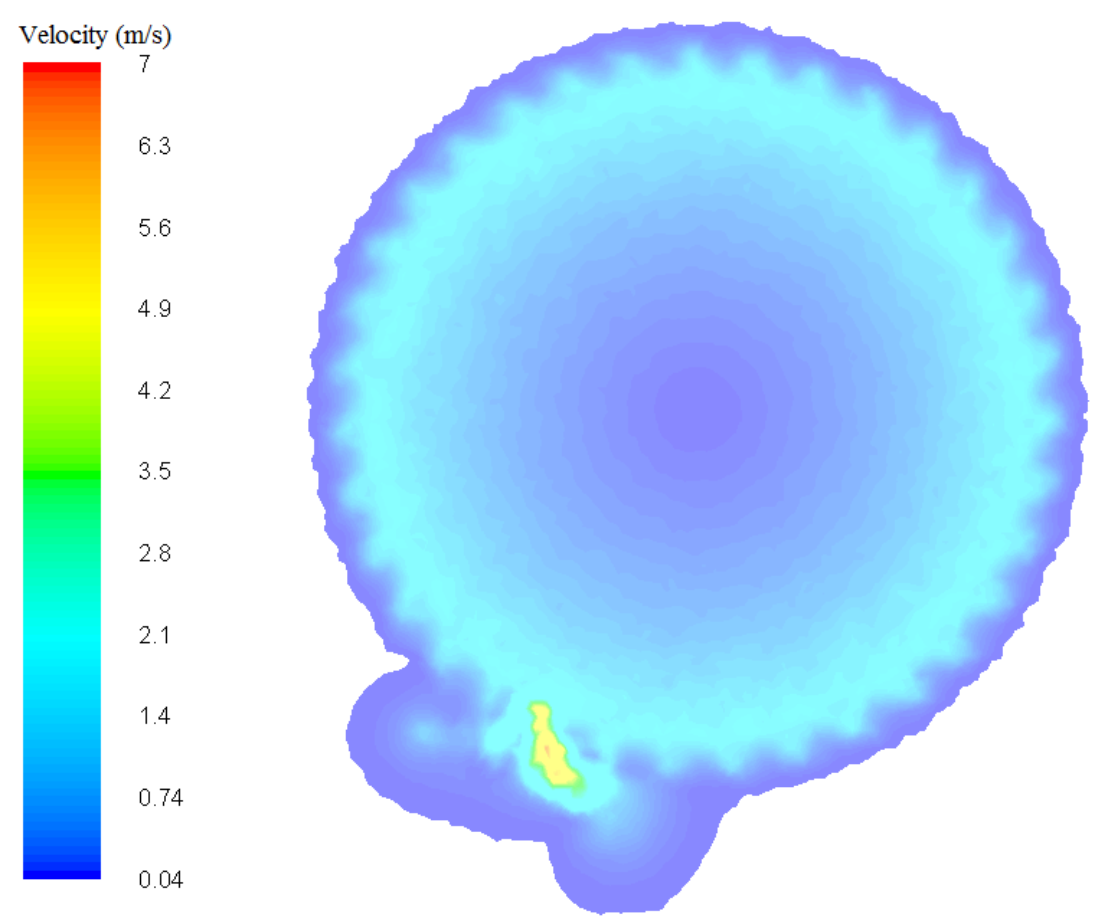

Figure 7: Contours of flow velocity at the outlet boundary

\section{(b)- Effect of volume fraction of lubricant in a jet and air-oil mist}

\section{system}

In order to simulate the effect of air-oil mist in the computational domain, it is assumed that the air-oil mixture is uniformly distributed with a constant lubricant volume fraction. This fraction is altered from zero VOF (dry sump) to 0.3 VOF in six steps to obtain the quantity of heat dissipation from rotating gear surfaces. The initial oil fraction in the gearbox is defined as:

$\emptyset_{\text {oil }}=\frac{V O F_{\text {oil }}}{\left(V O F_{\text {oil }}+V O F_{\text {air }}\right)}$

Figure 8 shows the effect of different lubricant VOF on the total heat transfer from the gear surfaces. The quantity of dissipated heat from the gear flank is increased with the liquid lubricant VOF in the transmission casing. The heat transfer coefficient for the teeth facing the oil jet (Figure 2) is mostly affected by the impinging oil jet. As the initial fraction of oil increases in the transmission casing, the adherent lubricant boundary layer on the gear flank surfaces grows. This formed boundary layer inhibits the cooling oil jet reaching the gear surface in an effective manner. Therefore, the heat transfer coefficient for these teeth 
decreases very slightly over time. However, the heat transfer coefficient for other teeth improves moderately. This is the reason for an overall increase in the rate of heat dissipation in Figure 8.

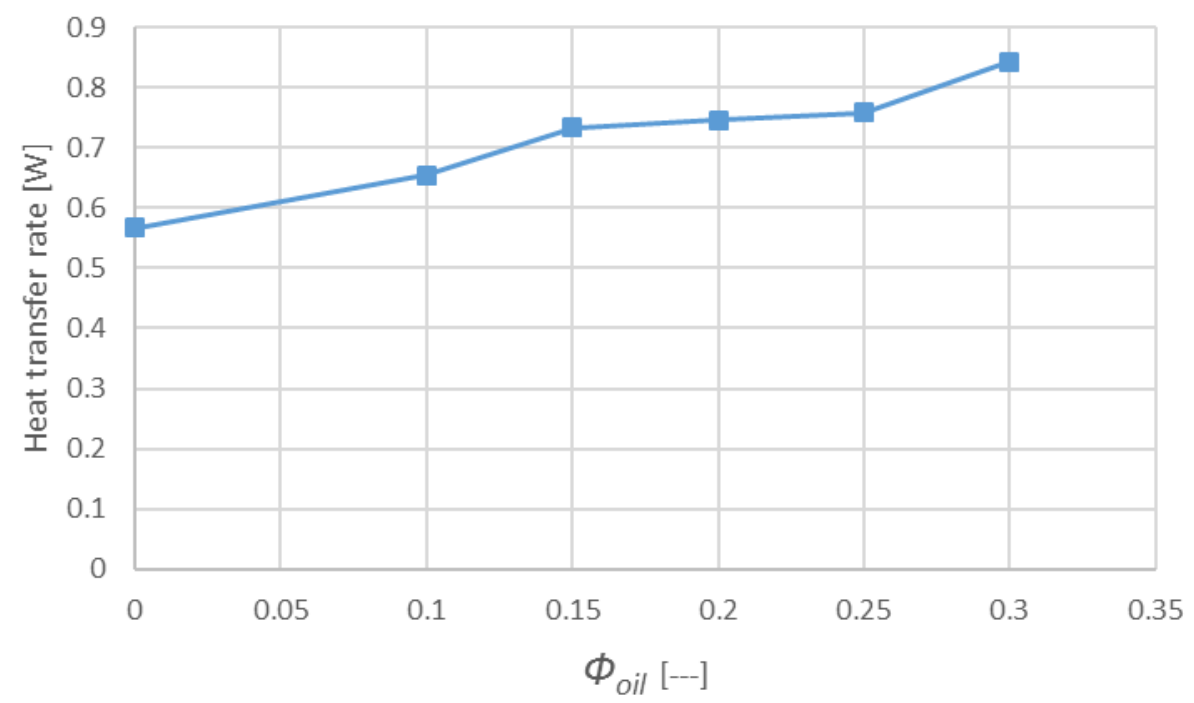

Figure 8: Heat dissipation from a rotating gear surface for different oil volume fractions

\section{(c)- Combined effect of impinging jet flow rate for a jet and air-oil mist system}

The effect is of the impinging oil jet is represented by the jet's Reynolds number, defined as:

$R e_{j}=\frac{\rho U_{j} D_{\text {nozzle }}}{\eta}$

In order to investigate the effect of impinging jet, its flow rate is altered from half to 1.5 times of the baseline flow rate of $0.0168 \mathrm{~kg} / \mathrm{s}$ in five steps. It is assumed that the transmission sump initially contains $20 \%$ liquid lubricant (i.e. $\Phi_{\text {oil }}=0.20$ ). Figure 9 represents the effect of oil jet's Reynolds number on the heat dissipation from the rotating gear. The heat dissipation from the gear flank consistently increases with the jet's Reynolds number, indicating a higher rate of cooling. 


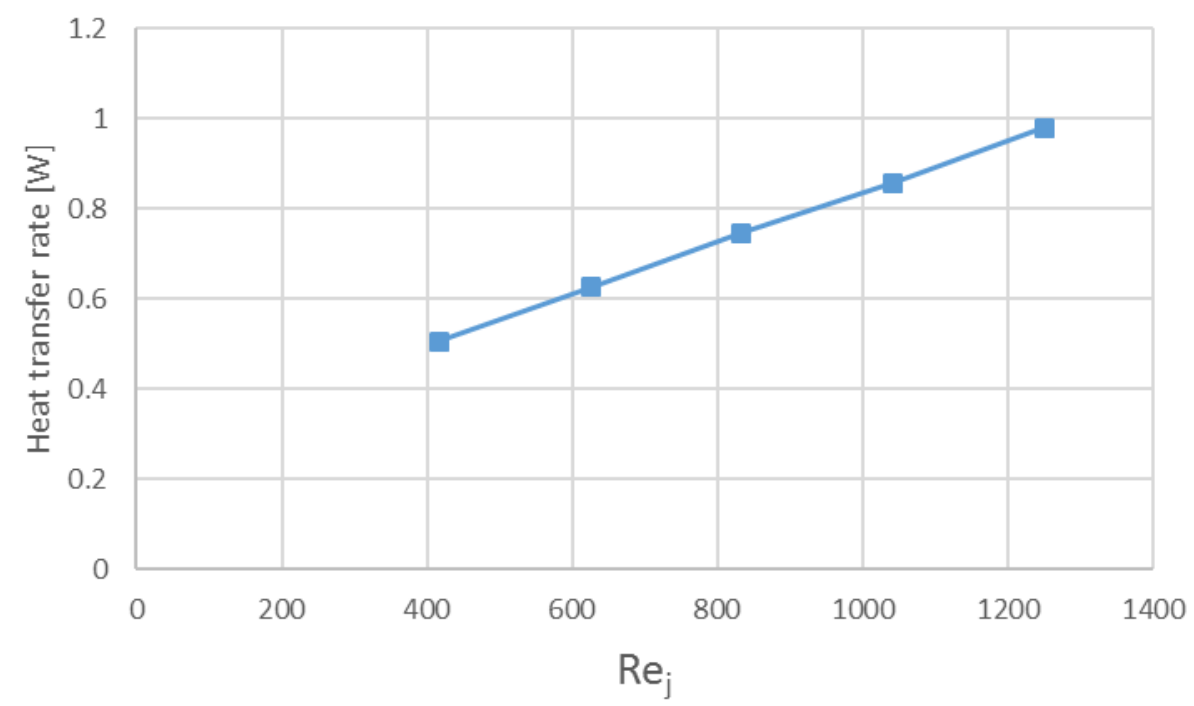

Figure 9: Heat dissipation variation for a rotating gear surface with oil jet Reynolds number

\section{(d)- Effect of gear rotational speed in a jet and air-oil mist system}

The variation of gear rotational speed, as indicated by its Reynolds number also affects the rate of cooling. The gear rotational Reynolds number is assumed to be equal to the equivalent disk Reynolds number [42] as:

$R e_{G}=\frac{\rho_{\text {air }} \omega D_{\text {pitch }}^{2}}{\eta_{\text {air }}}$

The gear speed is increased from half to 1.5 times the baseline gear speed of $114 \mathrm{rad} / \mathrm{s}$ in five steps. It is assumed that the transmission sump initially contains 20\% liquid lubricant (i.e. $\Phi_{\text {oil }}=0.20$ ). Figure 10 shows that the heat dissipation from the gear flank increases with gear speed because of the increased turbulent flow in the jet impinging area, which enhances the heat transfer rate. 


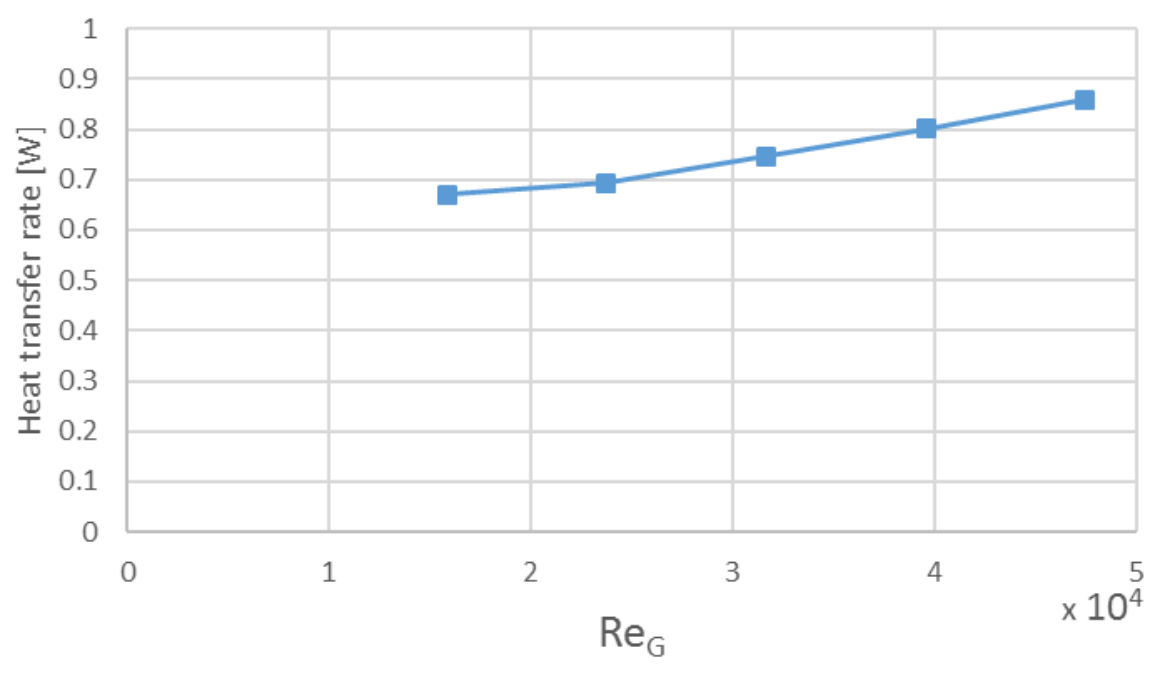

Figure 10: Heat dissipation variation for a rotating gear surface with gear rotational Reynolds numbers

\section{(e)- Effect of gear surface temperature in a jet and air-oil mist system}

The gear surface temperature also influences the heat dissipation rate. This is due to the change in the properties of the free surface adherent film mixture such as its viscosity, which also affects the turbulent flow. The temperature difference between the gear flank and the jet outlet is altered from half to 1.5 times the initial temperature difference of $13^{\circ} \mathrm{C}$ in five steps. The lubricant temperature at the nozzle exit and the housing temperature are kept constant at $100^{\circ} \mathrm{C}$ and $107^{\circ} \mathrm{C}$ respectively. It is assumed that the gearbox initially contains $20 \%$ liquid lubricant $\left(\Phi_{\text {oil }}=0.20\right)$. Figure 11 shows that an increasing temperature difference between the gear flank and the impinging jet directly affects the quantity of dissipated heat. 


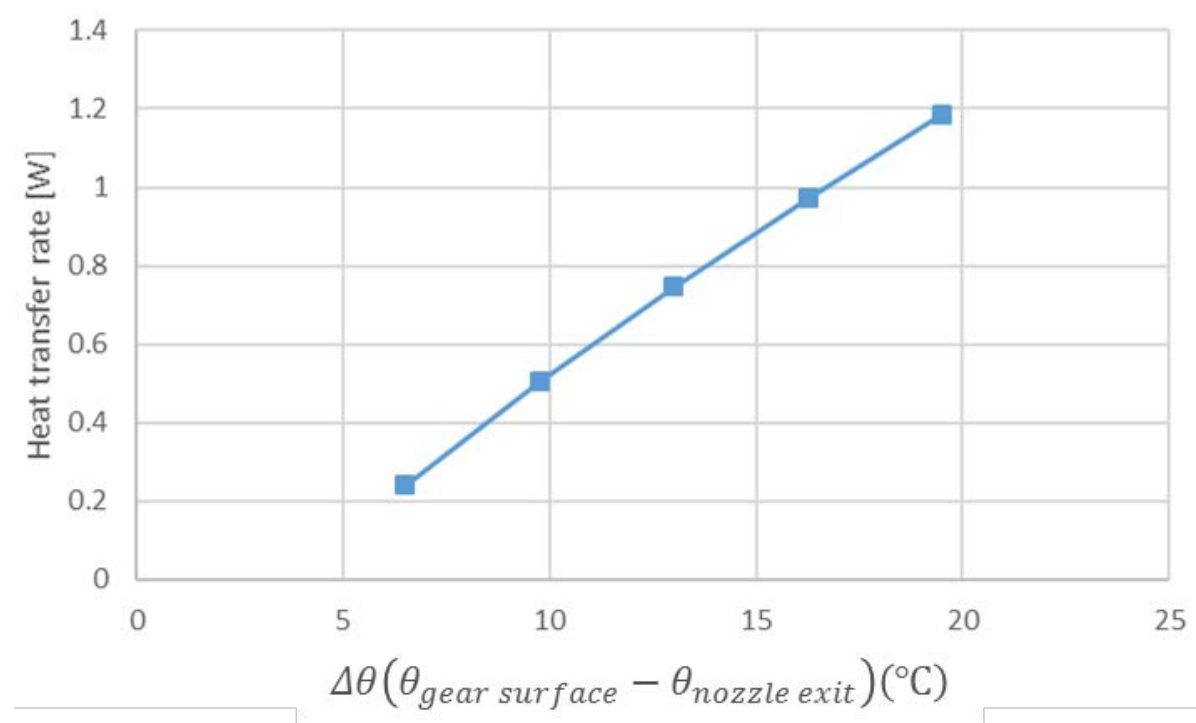

Figure 11: Heat dissipation variation for a rotating gear surface with gear surface temperature The increase in the heat dissipation with the temperature rise is due to the direct relationship between heat transfer and the temperature rise in equations (25) and (27). Additionally, an increase in temperature difference between the gear flank and the nozzle exit increases the heat transfer coefficient of the gear flank due to thermal mixing and turbulence. Figure 12 shows the increase in heat transfer coefficient for the gear teeth facing the impinging jet (Figure 2) and also for the other teeth.

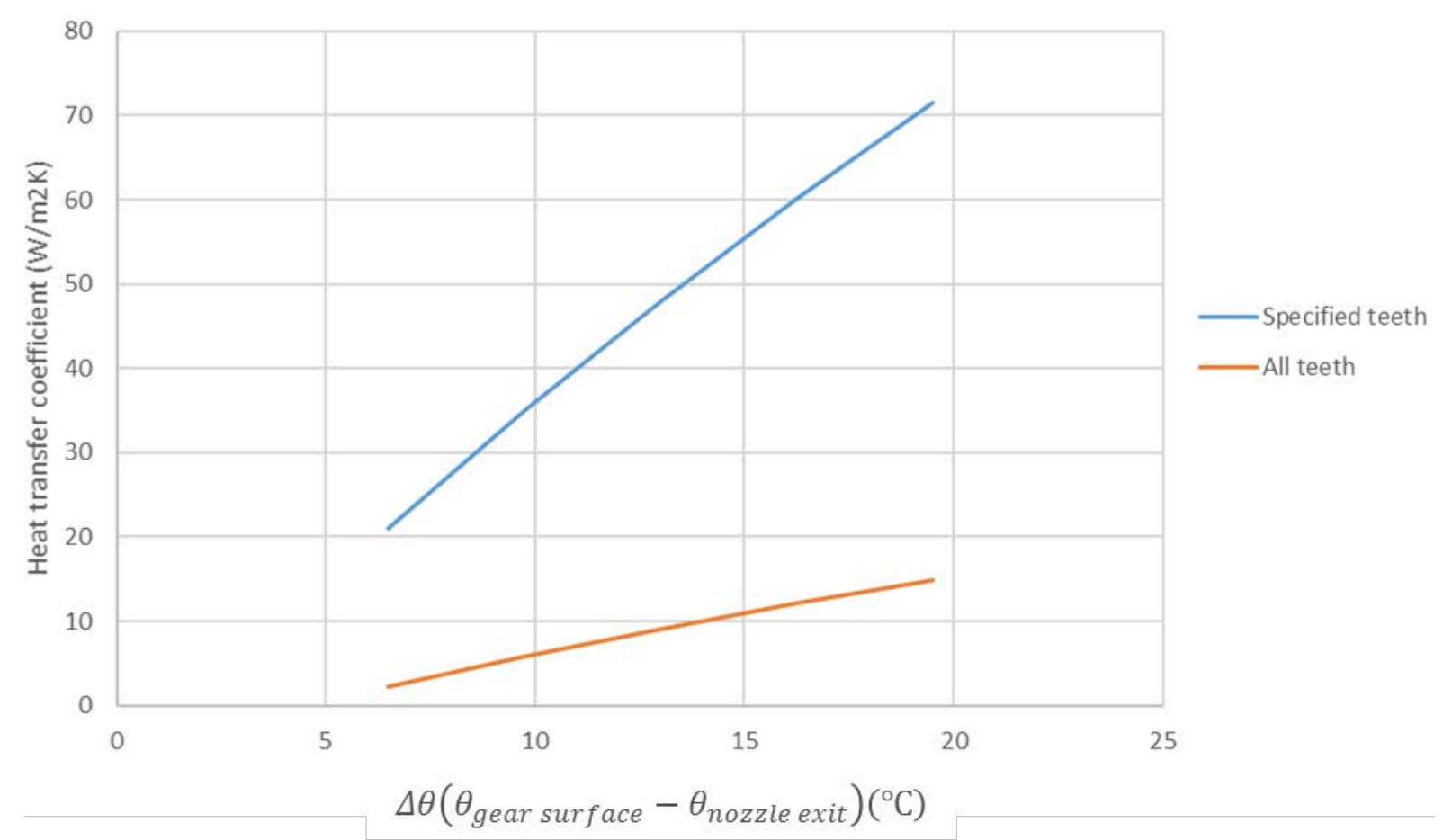

Figure 12: Effect of gear temperature increase on the heat transfer coefficient of gear flank 


\section{Regression Analysis}

The analysis method presented here is computationally intensive and thus difficult to implement to an entire transmission system. It is important to take the developed results into a more efficient model to enable prediction of thermal behaviour in dry sump transmissions and/or for air-oil mist systems. To achieve this, a multiple linear regression method is used to feed all the obtained results into a multi-variable function.

Two equations are developed. The first equation presents the Nusselt number for the gear teeth directly facing the oil jet. The thermal behaviour of these teeth is governed by the oil flow from the impinging jet. The second equation presents the Nusselt number for the remaining teeth, which are in contact with air in a dry sump system or with air-oil mist mixture in a mist lubricated transmission. The average heat transfer coefficient can be obtained from these Nusselt numbers as:

$h=\frac{\overline{N u} k}{D}$

\section{(a)- $\overline{N u}_{G}$ for teeth directly facing an oil jet}

The following Nusselt number equation is obtained for the teeth facing an impinging oil jet:

$\overline{N u}_{G}=0.516 \emptyset_{\text {oil }}^{-0.069} \operatorname{Re}_{j}^{0.898} \operatorname{Re}_{G}^{0.059} \theta^{* 1.122}$

where:

$\theta^{*}=\frac{\Delta \theta}{\theta_{\text {nozzle exit }}}$, and $\Delta \theta=\theta_{\text {gear surface }}-\theta_{\text {nozzle exit }}$

The difference between the values from equation (35) and those obtained numerically for the teeth facing the oil jet is less than $10 \%$.

\section{(b)- $\overline{N u}_{G}$ for the gear teeth not directly facing an oil jet}

The following regressed equation is obtained for the remaining gear teeth, not directly facing the jet flow, in contact with either air or an air-oil mixture:

$\overline{N u}_{G}=1.128 \emptyset_{\text {oil }}^{0.24} \operatorname{Re}_{j}^{0.41} \operatorname{Re}_{G}^{0.31} \theta^{* 1.756}$ 
The difference between the values from equation (36) and those obtained numerically for the other teeth than those directly facing the oil jet is less than $10 \%$.

Comparison of equations (35) and (36) shows relatively good agreement with the numerical results. According to equation (35), increasing $\Phi_{\text {oil }}$ decreases the heat dissipation rate from the teeth facing the oil jet. This is due to a thin boundary layer developed by an initial layer of lubricant, which prevents the impinging jet flow to readily reach the gear surface. The teeth facing the oil jet are affected more by the impinging jet. Therefore, $\overline{N u}_{G}$ for these teeth is influenced more by $R e_{j}$ than $R e_{G}$. The converse is true for $\overline{N u}_{G}$ (all the other gear teeth), which are affected by $\operatorname{Re}_{G}$. This is due to enhanced turbulent flow between the gear teeth and the surrounding mixture of oil and air.

\section{Conclusions}

An integrated numerical method, comprising a tribological heat generation model and a CFD heat dissipation model is presented. The heat dissipation from a rotating gear by an impinging oil jet is investigated. The power loss in a meshing cycle and the resulting temperature rise in the contact are obtained using an analytical thermo-elastohydrodynamic lubrication model. A 3D CFD model is developed to obtain the quantity of dissipated heat from the gear teeth surfaces. This is a novel approach, not hitherto reported in the literature. The developed model is based on validated methods. The results are qualitatively validated against analytical method in [16]. Experimental verification is clearly desirable. However, the current study deals with a pair of meshing gears, whilst the transmission system comprises many meshing pairs. Therefore, for future work a single gear pair rig needs to be designed and developed.

A baseline case of a passenger car transmission is considered, subjected to part of an NEDC specified manoeuvre. Different analyses are carried out in order to study the effects of various parameters on heat transfer rate through the gear surfaces. The results show that the maximum heat dissipation from the gear surface through an impinging jet, as well as an airoil mist environment is nearly $3.5 \%$ of the generated heat for a single gear. This indicates that the generated heat in the contact cannot be dissipated only through fluid-structure interactions. Other mechanisms such as heat conduction to other components and subsystems, as well as the effect of other jets impinging on non-selected gears contribute to thermal 
balance. The implication is that formation of baffles within a transmission system may be necessary to increase the contact time of a diminishing volume of the fluid medium with the structural members, which is a current trend in the development of modern dry sump transmissions. It is important to note that transient effect of conduction and convection cooling from the gear bodies should ideally be included in the overall model, using a finite element approach. This will provide a clearer picture of heat transfer mechanisms in meshing gears, and constitutes the future direction of this research.

The results are also used to obtain correlations for regressed $\overline{N u}_{G}$ in terms of dimensionless variables $\Phi_{\text {oil }}, R_{j}, \operatorname{Re}_{G}$ and $\theta^{*}$ for both directly wetted teeth by an oil jet and other gear teeth in an air-oil mist environment. These equations can be used for rapid predictions of heat transfer from an entire transmission, which would otherwise represent a computationally inhibitive analysis through use of a detailed model such as that presented in this study.

\section{References}

[1] Li, S. and Kahraman, A., "Prediction of spur gear mechanical power losses using a transient elastohydrodynamic lubrication model”, Tribology Trans., 2010, 53(4): 554-563.

[2] Mohammadpour, M., Theodossiades, S., Rahnejat, H. and Kelly, P., "Transmission efficiency and noise, vibration and harshness refinement of differential hypoid gear pairs”, Proc. IMechE, Part K: J. Multi-body Dynamics, 2014, 228(1): 19-33.

[3] Mohammadpour, M., Theodossiades, S. and Rahnejat, H., "Multiphysics investigations on the dynamics of differential hypoid gears”, J. Vibration and Acoustics, 136 (4): 041007

[4] Talbot, D.C., Kahraman, A. and Singh, A., "An experimental investigation of the efficiency of planetary gear sets”, Trans. ASME, J. Mechanical Design. 2012, 134(2): 021003.

[5] Mohammadpour, M., Theodossiades, S., Rahnejat, H. and Saunders T., "Non-Newtonian mixed elastohydrodynamics of differential hypoid gears at high loads”, Meccanica, 2014, 49(5): 1115-1138.

[6] Fatourehchi, E., Elisaus, V., Mohammadpour, M., Theodossiades, S. and Rahnejat, H., “Efficiency and durability predictions of high performance racing transmissions”, SAE Int. J. Passenger Cars-Mechanical Systems, 2016, 9(2016-01-1852). 
[7] Paouris, L., Theodossiades, S., De la Cruz, M., Rahnejat, H., Kidson, A., Hunt, G. and Barton, W., "Lubrication analysis and sub-surface stress field of an automotive differential hypoid gear pair under dynamic loading”, Proc. IMechE, Part C: J. Mechanical Engineering Science, 2016, 230(7-8): 1183-1197.

[8] Johns-Rahnejat, P.M. and Gohar, R., "Point contact elastohydrodynamic pressure distribution and sub-surface stress field”, In Tri-Annual Conference on Multi-Body Dynamics: Monitoring and Simulation Techniques, 1997, Bradford, UK.

[9] Seetharaman, S. and Kahraman, A., "Load-independent spin power losses of a spur gear pair: model formulation”, Trans. ASME, J. Tribology, 2009, 131(2): 022201.

[10] Seetharaman, S., Kahraman, A., Moorhead, M.D. and Petry-Johnson, T.T., “Oil churning power losses of a gear pair: experiments and model validation”, Trans. ASME, J. Tribology, 2009, 131(2):022202.

[11] Changenet, C. and Velex, P., "A model for the prediction of churning losses in geared transmissions_preliminary results”, Trans. ASME, J. Mechanical Design, 2007, 129(1):128133.

[12] Dawson, P.H., "Windage loss in larger high-speed gears”, Proc. IMechE, Part A: J. Power and Energy, 1984,198(1):51-59.

[13] Akin, L.S., “An interdisciplinary lubrication theory for gears (with particular emphasis on the scuffing mode of failure)". Trans. ASME, J. Engineering for Industry. 1973, 95(4):1178-1195.

[14] Akin, L.S., Mross, J.J. and Townsend, D.P., "Study of lubricant jet flow phenomena in spur gears”, Trans. ASME, J. Lubrication Technology, 1975, 97(2): 283-288.

[15] McCain, J.W. and Alsandor, E., "Analytical aspects of gear lubrication on the disengaging side”, Trans. ASLE. 1966, 9(2): 202-211.

[16] DeWinter, A. and Blok, H., "Fling-off cooling of gear teeth", Trans. ASME, J. Engineering for Industry, 1974, 96(1): 60-70.

[17] Fondelli, T., Andreini, A., Da Soghe, R., Facchini, B. and Cipolla, L., "Numerical Simulation of oil jet lubrication for high speed gears”, Int. J. Aerospace Engineering, 2015, Article ID 752457, 13 pp. 
[18] Vijayakar, S., “CALYX manual”, Advanced Numerical Solutions Inc, Columbus. Ohio, 2000.

[19] Xu, H. and Kahraman, A., "Prediction of friction-related power losses of hypoid gear pairs”, Proc. IMechE, Part K: J. Multi-body Dynamics, 2007, 221(3): 387-400.

[20] Karagiannis, I., Theodossiades, S. and Rahnejat, H., "On the dynamics of lubricated hypoid gears”, Mechanism and Machine Theory. 2012, 48: 94-120.

[21] Evans, C.R. and Johnson, K.L., "Regimes of traction in elastohydrodynamic lubrication”, Proc. IMechE, Part C: J. Mechanical Engineering Science, 1986, 200(5): 313324.

[22] Crook, A. W., "The Lubrication of Rollers III. A Theoretical Discussion of Friction and the Temperatures in the Oil Film". Phil. Trans. Royal Society of London A: Mathematical, Physical and Engineering Sciences, 254.1040, 1961: 237-258.

[23] Chittenden, R. J., Dowson, D., Dunn, J. F. and Taylor, C. M., “A theoretical analysis of the isothermal elastohydrodynamic lubrication of concentrated contacts. II. General Case, with lubricant entrainment along either principal axis of the Hertzian contact ellipse or at some intermediate angle”, Proc. Roy. Soc., Ser. A, 1985, 397: 271-294.

[24] Dowson, D. and Higginson, G.R., "Elasto-hydrodynamic lubrication: the fundamentals of roller and gear lubrication”, Pergamon Press; 1966.

[25] Greenwood, J. A. and Tripp J. H., "The contact of two nominally flat rough surfaces", Proc IMechE, 1970, 185: 625-633.

[26] Teodorescu, M., Balakrishnan, S. and Rahnejat, H., "Integrated tribological analysis within a multi-physics approach to system dynamics”, Tribology and Interface Engineering series, 2005, 48: 725-737.

[27] Gohar, R. and Rahnejat, H., "Fundamentals of Tribology", Imperial College Press, London, 2008.

[28] Mohammadpour, M., Theodossiades, S. and Rahnejat, H., "Transient mixed nonNewtonian thermo-elastohydrodynamics of vehicle differential hypoid gears with starved partial counter-flow inlet boundary”, Proc. IMechE, Part J: J. Engineering Tribology, 2014, 228(10): 1159-1173. 
[29] Hou, Q. and Zou, Z., “Comparison between Standard and Renormalization Group k-. EPSILON models in numerical simulation of swirling flow tundish”, ISIJ Int., 2005, 45(3): 325-330.

[30] Launder, B.E. and Spalding, D.B., "Lectures in mathematical models of turbulence”, Academic Press, London, England, 1972.

[31] White, F. M., "Viscous Fluid Flow", McGraw-Hill, 2nd Edition, 1991.

[32] Winterton, R.H., “Where did the Dittus and Boelter equation come from?”, Int. J. Heat and Mass Transfer, 1998, 41(4-5): 809-810.

[33] Hirt, C.W. and Nichols, B.D., "Volume of Fluid (VOF) Method for the Dynamics of Free Boundaries”, J. Computational Physics, 1981, 39: 201-225.

[34] Brackbill, J.U., Kothe, D.B. and Zemach, C., "A continuum method for modeling surface tension”, J. Computational Physics, 1992, 100: 335-354

[35] Eymard, R., Gallouët, T. and Herbin, R., "Finite volume methods", in: Handbook of numerical analysis, Vol. VII, 713-1020. Handbook of Numer. Anal., VII, North-Holland, Amsterdam. 2000.

[36] Barlow, T.J., Latham, S., McCrae, I.S. and Boulter, P.G., “A reference book for driving cycles for use in the measurement of road vehicle emissions”, Department of Transport, Cleaner Fuels and Vehicles 4, 2009, UK

[37] Norris, J., Walker, H., Stones, P. and Davies, R., "Assessing the efficacy of gear shift indicators", AEA/Millbrook, Oxford, UK, 2011.

[38] Wang, K.L. and Cheng, H.S., “A numerical solution to the dynamic load, film thickness, and surface temperatures in spur gears, part I: analysis”, J. Mechanical Design. 1981, 103(1):177-187.

[39] Long, H., Lord, A.A. Gethin, D.T. and Roylance, B.J., “Operating temperatures of oillubricated medium-speed gears: numerical models and experimental results”, Proc. IMechE, Part G: J. Aerospace Engineering, 2003, 217(2):87-106.

[40] Townsend, D.P. and Akin, L.S., “Analytical and experimental spur gear tooth temperature as affected by operating variables”, Trans. ASME, J. Mechanical Design. 1981, 103(1): 219-226. 
[41] Akin L.S., Mross, J.J. and Townsend, D.P., "Study of lubricant jet flow phenomena in spur gears”, Trans. ASME, J. Lubrication Technology, 1975, 97(2): 283-288.

[42] Carper H.J., Saavedra, J.J. and Suwanprateep, T., “Liquid jet impingement cooling of a rotating disk”, J. Heat Transfer, 1986, 108(3): 540-546. 